\title{
Seeking Editor for Clinical Liver Disease
}

The American Association for the Study of Liver Diseases (AASLD) is seeking an Editor for Clinical Liver Disease (CLD). CLD is an online, monthly, clinical, open access, free to users, multimedia clinical journal (see www.cldlearning.com).

CLD publishes 12 issues per year, each with 8-10 articles. Each article is accompanied by a video interview with the lead author, an audio podcast of the article, and in most instances a multiple choice examination question based on a key teaching point of the article. The Editor will work in close harmony with the publications teams at AASLD and the publisher (John Wiley).

Regular responsibilities of the Editor include:

- Select Editorial Board Members

- Select Guest Editors for each issue

- Select topics for monthly issues

- Monthly conference calls with the editorial board

- Edit content

- Conduct video interviews at medical meetings

Candidates for the position should:

- Be well-established and well-respected in academic hepatology and have a clear focus on clinical research/ education, with a high profile in the field

- Have a broad understanding of basic and clinical research in the field

- Be experienced in editorial decision making

- Be highly skilled in editing and writing

- Be comfortable with, and active on, social media

- Embrace innovative teaching and publication methods and platforms

- Be an AASLD regular or emeritus member throughout the complete tenure

The term will be July 2022 through December 2027. Content coordination has been and will continue to be through the AASLD central office in Alexandria, Virginia.

Each candidate should submit by April 23, 2021:

- A curriculum vitae

- Letters of support from the Dean and Department Chair of his or her academic affiliation

- A detailed statement outlining an assessment, editorial vision, and changes for CLD. Please do not name potential editorial team members in the application

The selection committee will review applications and will meet with finalists in September 2021, as part of the final selection process.

Please submit all applications to kmartinez@aasld.org by April 23, 2021.

Note: The selection committee will consider individuals suggested by third parties. Suggestions for individual candidates and candidate teams may be sent by email to kmartinez@aasld.org by March 26, 2021. 